\title{
De novo gastroesophageal reflux disease esophageal surgery in bariatrics: a literature review and analysis of the current treatment options
}

\author{
Rene Aleman, Emanuele Lo Menzo, Samuel Szomstein, Raul J. Rosenthal \\ Department of General Surgery and the Bariatric and Metabolic Institute, Cleveland Clinic Florida, Weston, FL, USA \\ Contributions: (I) Conception and design: R Aleman, E Lo Menzo, RJ Rosenthal; (II) Administrative support: S Szomstein, RJ Rosenthal; (III) \\ Provision of study materials or patients: E Lo Menzo, S Szomstein, RJ Rosenthal; (IV) Collection and assembly of data: R Aleman; (V) Data analysis \\ and interpretation: E Lo Menzo, R Aleman; (VI) Manuscript writing: All authors; (VII) Final approval of manuscript: All authors. \\ Correspondence to: Raul J. Rosenthal, MD, FACS, FASMBS. Chairman, Department of General Surgery and Director, Bariatric and Metabolic \\ Institute, Cleveland Clinic Florida, 2950 Cleveland Clinic Blvd, Weston, FL 33331, USA. Email: rosentr@ccf.org.
}

\begin{abstract}
With the exponential increase of worldwide obesity, the number of bariatric surgery $(\mathrm{BaS})$ procedures have equally risen. The surgical management of obesity has been widely established as the standard of care for sustained weight reduction, resolution, and improvement of associated comorbidities. However, $\mathrm{BaS}$ itself can have postoperative deleterious effects, including de novo gastroesophageal reflux disease (GERD) and upper gastrointestinal motility disorders. The modified anatomy resulting from $\mathrm{BaS}$, due to either a restrictive or hypoabsorptive component, gives this disorder a multifactorial etiology. The overall management of de novo GERD should focus on three primordial approaches: Non-surgical, endoluminal, and surgical. Even in the absence of de novo GERD following primary or secondary BaS, said disorder should be closely monitored and therapy should be catered in a case-by-case approach. Consequently, treatment strategies have been developed on this principle as to adequately resolve de novo GERD. Despite the presence of multiple and suitable treatment modalities, the operating surgeon should perform them in the best interest of the patient. Short-, medium-, and long-term outcomes should be taken into consideration prior to proceed with any type of preferred management option. This article herein presents an update on the surgical management of de novo GERD following BaS and current practical innovations.
\end{abstract}

Keywords: De novo gastroesophageal reflux disease (de novo GERD); GERD; esophageal surgery; bariatrics; bariatric surgery $(\mathrm{BaS})$

Submitted Aug 15, 2020. Accepted for publication Nov 09, 2020.

doi: 10.21037/atm-20-5890

View this article at: http://dx.doi.org/10.21037/atm-20-5890

\section{Introduction}

Over the past three decades, the prevalence obesity has doubled worldwide (1). In the United States (US) alone, obesity has reached a prevalence of roughly $36 \%$ in adults over the age of $20(1,2)$. Esophageal disorders-like gastroesophageal reflux disease (GERD)—are common in the obese population prior, following, or in spite of bariatric intervention. In consideration of the anatomical and physiological implications of modern bariatric surgery $(\mathrm{BaS})$, there is a continuing concern for the development of de novo GERD in both restrictive and hypo-absorptive surgeries. Clinically, GERD symptoms have been reported in 35\% to $70 \%$ of obese patients who are suitable candidates for $\mathrm{BaS}$ (3-5). However, due to the low predictive value of symptoms alone for the diagnosis of GERD, objective measurements before $\mathrm{BaS}$ are warranted for comprehensive therapeutic management.

In addition to the predisposition of obese individuals 
to GERD, BaS can also contribute to the worsening or de novo development of GERD. Both the anatomical and physiological changes determined by surgery are responsible for these effects. Among the proposed mechanisms, lower esophageal sphincter (LES) hypotension, decreased gastric compliance and volume, delayed gastric emptying, and decreased plasma ghrelin levels are the most commonly described. In this regard, the type of $\mathrm{BaS}$ plays a significant role. Numerous surgical techniques have been implemented and modified in hopes to avoid the development of said disorders. Despite the constant improvement in the practice of $\mathrm{BaS}$, de novo GERD continues to occur in a collective incidence of $20 \%$ after primary SG (6). Consequently, primary BaS should emphasize the development of strategies for both prevention and management of de novo or recurrent GERD after surgery. This review focuses on the identification of GERD associated with BaS and summarizes current management and future directives.

\section{Pathophysiology: relationship between obesity, BaS, and GERD}

De novo GERD can be a detrimental complication of obesity and $\mathrm{BaS}$ alike with the evident potential of reducing the patients' quality of life. The premise that obesity has a direct impact in the development of GERD, was firstly described by Lundell and Wajed $(7,8)$. Despite the variability of their results, the hypothesis of the pathophysiology of GERD in obese patients is still valid. Nevertheless, there are several other mechanisms of actions that have been suggested. To further elaborate, large prospective studies have confirmed the high prevalence of GERD symptoms and abnormal $\mathrm{pH}$ metric and manometric findings in patients with obesity (9). In fact, it has been shown how patients with increased body mass index (BMI) with no GERD-related symptoms, could have abnormal DeMeester scores $(\mathrm{pH}<4)(10,11)$. Analogously, the resulting chronic increase in intrabdominal pressure secondary to a high $\mathrm{BMI}$ has shown a significant risk for the presence of a hiatal hernia $(\mathrm{HH})(7,12-17)$. Additionally, the proliferative increase in gastrointestinal hormones associated to an increased BMI have could be responsible for the $9 \%$ increased risk of Barrett's esophagus, a twofold increase risk of adenocarcinoma, and a 2.5 increase risk of developing a $\mathrm{HH}$, that may unequivocally lead to GERD (14,17-19). Altogether, the three main mechanisms of GERD resulting from obesity are as follow: (I) increased prevalence of a $\mathrm{HH}$; (II) increased intraabdominal pressure; and (III) esophageal motility disorders, including abnormal LES (decreased basal pressure and/or increased transient relaxations of the LES) $(3,10,17,20)$.

Although obesity is a risk factor in the development or recurrence of GERD, BaS plays a role in this disease. The restrictive, hypo-absorptive, and mechanical aspects of bariatric procedures can increase the risk for de novo GERD despite the conservation of weight loss and resolution of obesity-related comorbidities. Notwithstanding the known short-, medium, and long-term mechanical and physiological consequences of $\mathrm{BaS}$, there is discrepancy in the true effects of these procedures in GERD or de novo GERD. To that extent, a recent randomized controlled trial failed to determine a significant risk of de novo GERD between SG and RYGB (21). Similarly, another randomized controlled trial suggested that the high incidence of GERD after SG may be due to surgeon bias proclivity to suggest performing SG, rather than an inherent property of the procedure itself (22). Evidently, it is of great clinical significance to establish whether or not there is a truthful relationship between $\mathrm{BaS}$ and de novo GERD. To date, however, there appears to be no consensus in regards to the aforementioned.

In the presence of said dilemma, a systematic analysis and review of the literature was performed in order to investigate the relationship between SG and RYGB, and de novo GERD development. In order to ascertain a suitable conclusion, the authors of this study extracted the number of obese patients with newly onset, worsened, or improved GERD after BaS in each of the selected articles. After performing a pool analysis SG was associated with a higher risk of GERD rather than RYGB [odds ratio $(\mathrm{OR})=5.10$, with a $95 \%$ confidence interval $(\mathrm{CI}), \mathrm{P}<0.001]$. When comparing both procedures, RYGB had a better effect on GERD (OR $=0.19,95 \%$ CI, $\mathrm{P}<0.001$ ). Additionally, RYGB was more effective in the treatment of GERD in obese patients than SG, and the incidence of de novo GERD after RYGB was lower (23).

Very few studies in the literature have examined motility disorders among the morbidly obese population in general, outside the context of GERD. Koppman et al., performed a retrospective analysis of 116 obese patients that underwent manometric esophageal evaluation prior to surgical intervention. The evaluated tracings consisted of LES resting pressure, LES relaxation, and esophageal peristalsis. The mean BMI for the patient cohort was $42.9 \mathrm{~kg} / \mathrm{m}^{2}$, and a mean age of 48.6 years. Forty one percent of the patients showed abnormal esophageal findings, including nonspecific esophageal motility disorders (23\%), 
Table 1 Mechanisms for esophageal disease based on type of BaS

\begin{tabular}{ll}
\hline Effect of BaS & Esophageal disorder \\
\hline SG $(12,21,24)$ & \\
Hypotonic LES & GERD recurrence and de novo \\
$\begin{array}{l}\text { Sleeve migration leading to decreased gastric } \\
\text { compliance and high intragastric pressure }\end{array}$ & Increased gastric emptying \\
$\begin{array}{l}\text { Inadequate takedown of the sling fibers at the } \\
\text { EGJ leading to incompetent junction }\end{array}$ & HH \\
RYGB (24,25) & Inadvertent resection of the phreno-esophageal ligament \\
Malabsorption & GERD improvement \\
Hypotensive LES & Minimal-to-none esophageal disorders; dysphagia-insufficient and opposing evidence \\
\hline
\end{tabular}

SG, sleeve gastrectomy; RYGB, Roux-en-Y gastric bypass; BaS, bariatric surgery; LES, lower esophageal sphincter; GERD, gastroesophageal reflux disease; EGJ, esophagogastric junction; $\mathrm{HH}$, hiatal hernia.

nutcracker esophagus (peristaltic amplitude $>180 \mathrm{mmHg}$ ) $(11 \%)$, isolated hypertensive LES pressure $(>35 \mathrm{mmHg})$ (3\%), isolated hypotensive LES pressure ( $<12 \mathrm{mmHg})(3 \%)$, diffuse esophageal spasm (1\%), and achalasia (1\%). Only one patient with abnormal esophageal motility reported non-cardiac chest pain. The study concluded that despite the high prevalence of esophageal dysmotility in this patient population, there is a conspicuous absence of symptoms (24).

Oor and colleagues found that the hazard ratio of newly onset GERD after SG was $4.3 \%$ compared with that before surgery, with an approximate incidence of $20 \%$ (25). It has been proposed that the LES pressure drop is an important cause of GERD after SG (26). Regarding surgical technique, the obliteration of the angle of His and the proximal displacement in the creation of the sleeve at the level of the hiatus, were both identified as structural causes for GERD $(27,28)$. These findings suggest that the structural integrity of the sleeve might be the fundamental principle on which de novo GERD relies for its occurrence. It also poses the question on whether or not the surgeon should decide to incline towards an SG redo or a conversion to RYGB.

In essence, the implications on the relationship between GERD and BaS are both numerous and complex (Table 1). The heterogeneity in the literature prevents from drawing definitive conclusions of the direct effects of $\mathrm{BaS}$ in GERD development. To highlight this principle, many studies rely on symptoms and drug efficacy for the diagnosis of GERD. The lack of objective evaluation, such as manometry, hinders an accurate diagnosis of GERD. Furthermore, long-term complications of $\mathrm{BaS}$ require an equal long- term follow-up. The inconsistency of diagnostic methods, type of bariatric procedure, follow-up, and study designs, further suggest that the assumptions of $\mathrm{BaS}$ on GERD (previously diagnosed or de novo) deem detailed analysis and interpretation. Ultimately, the surgeon should individualize each case to achieve a comprehensive understanding of the risks in the development of esophageal disorders prior to planning a surgical intervention.

\section{Diagnosis}

The confirmatory diagnosis of GERD is mandatory prior to treatment. Also, it is paramount to attempt the identification of a mechanical, anatomical or functional disorder. The mainstay of diagnosis are upper gastrointestinal series (UGI), and an esophagogastroscopy (EGD).

Initially, an UGI will provide an evaluation of the anatomy of the foregut, possibly identifying volume type of reflux $(29,30)$. The EGD, in addition to anatomical derangements, will provide information regarding mucosal and endoluminal, in general, abnormalities. Although, the systematic performance of this evaluation has low probability of modifying the surgical plan prior to the original $\mathrm{BaS}$, it has been prove to be very helpful in the strategic assessment of revisional procedures $(31,32)$.

The role of routine preoperative $\mathrm{pH}$ study remains controversial. A study was performed to determine the preemptive monitoring capabilities of preoperative wireless $\mathrm{pH}$ monitoring (WPHM) on the development or worsening of GERD prior to BaS. The study centered on the evaluation of preoperative objective measurement of acid 
Table 2 Contemporary surgical therapies for GERD management following BaS

\begin{tabular}{lll}
\hline Technique & Advantage & Disadvantage \\
\hline Modified Nissen fundoplication (36,37) & $\begin{array}{l}\text { 360 degrees fundoplication with the excluded } \\
\text { gastric remnant }\end{array}$ & Lack of large studies; lack of long-term data \\
HHR with barbed suture (38) & $\begin{array}{l}\text { Technically simpler; equal distribution of tension } \\
\text { along suture line }\end{array}$ & $\begin{array}{l}\text { Lack of randomized trial comparing with other } \\
\text { types of repairs }\end{array}$ \\
Re-SG* $(39,40)$ & Technically simpler than conversional surgery & Lack of large studies; lack of long-term data \\
Conversion to RYGB* (if primary BaS is & Most effective acid suppressive treatment & Potential morbidity \\
SG) (41) & Applicable to SG, RYGB and BPD-DS & Not standardized technique; lack of large \\
Antireflux valve (ARV) (42) & & studies; lack of long-term data \\
LINX reflux management system (43) & Potentially Less invasive & Lack of large studies; lack of long-term data; \\
\end{tabular}

*, revisional BaS. HHR, hiatal hernia repair; SG, sleeve gastrectomy; GERD, gastroesophageal reflux disease; RYGB, Roux-en-Y gastric bypass; BaS, bariatric surgery; RYGB, Roux-en-Y gastric bypass; BPD-DS, biliopancreatic diversion-duodenal switch.

reflux by using wireless $\mathrm{pH}$ monitoring and its impact on surgical planning and outcomes. Based on the acquired data by measurement of GERD, using WPHM compared with preoperative EGD alone aids in a better patient selection for either SG or RYGB. The preoperative close monitoring of pre-existing or de novo GERD via WPHM showed no postoperative surgical conversions or revisions (33).

\section{Indications}

The surgical management of esophageal disorders is well known. Surgical therapy has proven to be comparatively effective as medical treatment alone, and serve as an adequate and effective alternative for the satisfactory control of failed pharmacologic therapy (34). BaS appears to have a greater impact on GERD recurrence or de novo GERD when compared to motility disorders, mainly due to the anatomical construct of the respective malabsorptive and restrictive operations (6). If esophageal disorders do occur, the focus of the intervention should aim for the improvement of the patient's quality of life via symptomatic relief.

In the presence of GERD after $\mathrm{BaS}$ not responsive to non-operative treatment, the decision of the surgical therapy option should be made based on the primary bariatric procedure and overall clinical scenario. Obviously, some of the most effective traditional anti-reflux techniques, such as complete and partial fundoplications, are usually not doable. Additionally, the presence or absence of a $\mathrm{HH}$ should be thoroughly investigated for its direct influence on GERD and appropriately repaired at the time of revisional/conversional surgery (35). Table 2 summarizes the current available techniques for GERD. A recent metaanalysis showed a low rate of conversion of SG to RYGB due to severe GERD (23). Similar studies have shown SG conversion proportions in about $4 \%$ of patients, mainly due to severe reflux and weight loss failure (44-46). The diagnosis of GERD based on symptoms and drug efficacy has been reported to have a sensitivity of $53.4 \%$ and specificity of $68.4 \%$ (47).

\section{Treatment options}

Significant progress and changes have been made in the scheme of GERD treatment. Although life-style modifications remain the cornerstone of any therapeutic intervention for GERD, medical, surgical, and endoluminal therapies are to be considered for a comprehensive and adequate approach.

\section{Non-surgical}

Lifestyle modifications, dietary changes, and medical therapy are the first treatment for post BaS GERD. Lifestyle modifications include avoidance of flat recumbent position by raising the head end of the bed, avoidance meals 3 hours prior to lying down, avoidance of smoking, and weight loss. The dietary changes include, not only, the modification necessary to aid in weight loss, but also the avoidance of all those "pro-reflux" aliments, such as chocolate, caffeine, citrus, mint, or spicy food. However, 
a systematic review of clinical trials examined the impact of lifestyle modifications on GERD based on changes in symptoms, esophageal $\mathrm{pH}$ variables, or LES basal pressure. The study concluded that there is insufficient evidence to suggest these modifications lead to a clinical improvement or changes of the physiological parameters of GERD (48). In contrast, obesity has shown a direct correlation as a risk factor for the development or worsening of GERD. in this regard, a large cohort study demonstrated that even modest weight gain can exacerbate GERD symptoms and that women who reduce their BMI by 3.5 units or more will have a $40 \%$ reduction in the frequency of GERDrelated symptoms compared to controls (49). Additional, less studied, lifestyle modifications should also be recommended. For example, the improvement of a patient's sleeping hygiene will help reduce symptoms by suppressing transient lower esophageal sphincter relaxations (TLESR), a study sowed (50).

In patients with persistent symptoms it is necessary to add pharmacological therapy. Medical therapy includes: antacids (combination of magnesium trisilicate, aluminum hydroxide or calcium carbonate), raft-forming agents (alginate), cytoprotective agents (sucralfate, prostaglandin analogs), inhibitors of the acid secretion (histamine 2 receptor antagonists (H2RAs), proton-pump inhibitors (PPIs), TLESR reducers [gamma-aminobutyric acid (GABA)-B agonists], and prokinetic agents (cisapride, metoclopramide, domperidone). Overall, PPIs are the most widely used medical therapy with a satisfactory range between $56 \%$ to $100 \%$ (51). In fact, PPIs significantly improve symptom response rate as compared with H2RAs, as well as healing of erosive esophagitis, and preventing relapse of both symptoms and esophageal inflammation (52). In summary, medical therapy, regardless of the type of medication tailored for each patient, should always focus on the lowest dose to control symptoms. The need for chronic medical therapy should be evaluated on a regular basis and alternative options in refractory or worsening cases should be sought and offered to patients.

\section{Endoluminal}

Due to the less invasive and safety aspect of endoluminal therapies, the development of said techniques have risen over the past two decades. Initially, the endoluminal therapies were limited to four types: Fixation, ablation, injection, and mucosal excision and suturing. Presently, however, there are only two widely accepted endoluminal techniques: Radiofrequency treatment of the LES (Stretta procedure), and Transoral Incisionless Fundoplication (TIF) (Esophy $\mathrm{X}^{\circledR}$ Endogastric solutions, Redmond, WA, USA). Both procedures have shown promising results, however the long-term benefits remain limited. The EsophyX is used to restore the angle of His by creating a valve at the esophagogastric junction (EGJ), achieved by applying multiple full thickness, nonabsorbable fasteners. Since its clinical introduction, the randomized EsophyX versus Sham placebo-controlled trial (RESPECT), a multicenter study conducted at eight centers in the US, reported that this device better controls heartburn than the sham procedure off medication (53). Contrastingly, the Stretta device consists of a balloon-tipped four-needle catheter that delivers radiofrequency energy into the smooth muscle of the EGJ. Multiple studies have been performed since its introduction, 16 years ago. In spite of its conflicting reported outcomes, evidence suggests that the Stretta device is an effective therapeutic tool for patients with GERD $(54,55)$.

\section{Surgical}

Currently RYGB continues to be the standard conversion procedure in the presence of intractable GERD after primary SG, showing complete resolution of symptoms (56). Other alternatives like the LINX device have been developed with similar or suboptimal results, deeming them unfit for a true resolution of this condition (43).

Some less commonly practiced alternatives may be considered by more experienced bariatric surgeons. Due to the anatomical impact of both restrictive and malabsorptive procedures, traditional fundoplications as surgical therapy for GERD, are not an option following BaS. The only exception is the modified Nissen fundoplication that has yet to be comprehensively described in the literature.

In the presence of a $\mathrm{HH}$ with no LES complex abnormalities, the priority should focus on the correction of the defect due to the mechanical impact of it on the clinical symptoms of GERD. Among the different techniques for hiatal hernia repair (HHR), the use of barbed suture has recently gained popularity, based on the technical simplicity and durable results. In a retrospective review comparing 150 patients who underwent $\mathrm{HH}$ after $\mathrm{BaS}$ either by barbed sutures or standard repair, no difference was found between the two techniques (38). This technique requires further studies to validate the short- and longterm outcomes. However, the ease and technical dextrality 
that barbed suture offers in the laparoscopic setting, deems it a technique to take into consideration as a promising alternative to conventional methods on HHR.

Although the traditional fundoplications are not an option after a bariatric procedure, other options have been described in the literature using the fundus of the stomach for different types of "gastroplasties", antireflux valve (ARV), and modified fundoplications. Antireflux techniques by means of hiatoplasty and 180 degrees cardioplication have proven improvement of preexisting GERD and resolution in 61.4\% (57). However recent data suggest that the use of these modified fundoplications concomitantly with SG did not result in resolution of symptoms and in the rate of need for conversion to gastric bypass (41). The ARV has been proposed as a surgical technique to avoid GERD after SG and RYGB. However, it can be used during revisional SG surgery in the presence of a dilated fundus. ARV aims to restore the function of the GE junction and its anti-reflux mechanism by recreating the acute angle of His. In a prospective study that analyzed 864 patients, this technique prevented and successfully treated the GERD caused or aggravated by the primary $\mathrm{BaS}$ (42). The modified Nissen fundoplication is only applicable as a laparoscopic ant reflux surgery after primary RYGB. The procedure consists of a laparoscopic 360 degrees fundoplication to reinforce the LES by wrapping the excluded stomach around the lowest portion of the esophagus (36). Comparatively, the only other surgery described for persistent reflux similar to this modified Nissen technique, was a conventional 270 degrees Belsey Mark IV ant reflux surgery following open RYGB (37). The novelty and rarity of this surgery raises an interesting topic for future prospective studies directed in the interest of determining the true long-term impact of this procedure.

As previously mentioned, evident anatomic abnormalities of the SG can be responsible for GERD. In particular the presence of a voluminous gastric fundus, either left at the time of surgery, or developed overtime, acts as a reservoir and promotes GERD. In these cases, re-sleeving (dilated gastric pouch or large residual gastric fundus) has been utilized with success $(6,39,40)$. There is however, heterogenous opinions on the impact of primary SG or re-sleeving following a primary SG. Both weight loss and reflux outcomes associated with SG have been found to vary considerably based on surgeon's technique, and ultimately the shape of the completed gastric sleeve (58). There is a lack of consensus amongst surgeons on the appropriate practice of "re-sleeving" in the setting of pathologic GERD.
The objective data on clinical symptoms, monitoring, and need of medical therapy, indicate that when compared to RYGB, SG outcomes provide insignificant improvement in the presence of GERD (59).

The anatomical characteristics of RYGB seem to be ideal for reduction of GERD. In fact, the creation of a small pouch based on the lesser curvature decreases the production of acid. Also, the diversion of bile with a Roux limb of 100-150 cm, prevents bile reflux. Finally, the expected significant weight loss will decrease the intrabdominal pressure, ultimately having a positive effect on the reduction of reflux. After RYGB, GERD reportedly improves by $90 \%$, and reflux esophagitis decreases from $45 \%$ to $19 \%(60,61)$. On the other end, however, de novo GERD is possible after RYGB. The disruption on the integrity of the esophageal sphincter following the dissection of the phrenoesophageal membrane for stapler placement adjacent to the angle of His, might play an advertent role in GERD development (62). In addition, the incidence of non-acid reflux might reportedly increase after RYGB, likely due to narrowing at the gastro-jejunal anastomosis or to a short alimentary limb (63).

\section{Conclusions}

Esophageal disorders, mainly GERD, are common in obese individuals. Although $\mathrm{BaS}$ may improve some of the symptoms, a certain percentage of patients will develop de novo GERD. The treatment of de novo GERD should be individualized and tailored to the underlying causative effect. Hence a thorough preoperative multidisciplinary assessment is mandatory. When non-operative treatment fails, surgical intervention can be very effective. Although not an ideal procedure exists, of the several options available, RYGB remains the most utilized based on its effectiveness. Novel endoluminal techniques lack, however, sufficient evidence to translate them into standard clinical practice.

\section{Acknowledgments}

Funding: None.

\section{Footnote}

Provenance and Peer Review: This article was commissioned by the Guest Editor (Dr. Ory Wiesel) for the series "Innovations and Updates in Esophageal Surgery" published in Annals of Translational Medicine. The article has 
undergone external peer review.

Conflicts of Interest: All authors have completed the ICMJE uniform disclosure form (available at http://dx.doi. org/10.21037/atm-20-5890). The series "Innovations and Updates in Esophageal Surgery" was commissioned by the editorial office without any funding or sponsorship. The authors have no other conflicts of interest to declare.

Ethical Statement: The authors are accountable for all aspects of the work in ensuring that questions related to the accuracy or integrity of any part of the work are appropriately investigated and resolved.

Open Access Statement: This is an Open Access article distributed in accordance with the Creative Commons Attribution-NonCommercial-NoDerivs 4.0 International License (CC BY-NC-ND 4.0), which permits the noncommercial replication and distribution of the article with the strict proviso that no changes or edits are made and the original work is properly cited (including links to both the formal publication through the relevant DOI and the license). See: https://creativecommons.org/licenses/by-nc-nd/4.0/.

\section{References}

1. World Health Organization. Global Status Report on Noncommunicable Diseases 2014. 2015.

2. Flegal KM, Kruszon-Moran D, Carroll MD, et al. Trends in Obesity Among Adults in the United States, 2005 to 2014. JAMA 2016;315:2284.

3. Suter M, Dorta G, Giusti V, et al. Gastro-esophageal reflux and esophageal motility disorders in morbidly obese patients. Obes Surg 2004;14:959-66.

4. Schauer PR, Ikramuddin S, Gourash W, et al. Outcomes after laparoscopic Roux-en-Y gastric bypass for morbid obesity. Ann Surg 2000;232:515-29.

5. Fisher BL, Pennathur A, Mutnick J, et al. Obesity correlates with gastroesophageal reflux. Dig Dis Sci 1999;44:2290-4.

6. Treitl D, Nieber D, Ben-David K. Operative Treatments for Reflux After Bariatric Surgery: Current and Emerging Management Options. J Gastrointest Surg 2017;21:577-82.

7. Lundell L, Ruth M, Sandberg N, et al. Does massive obesity promote abnormal gastroesophageal reflux? Dig Dis Sci 1995;40:1632-5.

8. Wajed SA, Streets CG, Bremner CG, et al. Elevated body mass disrupts the barrier to gastroesophageal reflux. Arch
Surg 2001;136:1014-8; discussion 1018-9.

9. Merrouche M, Sabaté JM, Jouet P, et al. Gastro-esophageal reflux and esophageal motility disorders in morbidly obese patients before and after bariatric surgery. Obes Surg 2007;17:894-900.

10. Hong D, Khajanchee YS, Pereira N, et al. Manometric abnormalities and gastroesophageal reflux disease in the morbidly obese. Obes Surg 2004;14:744-9.

11. Nilsson M, Johnsen R, Ye Weiming, et al. Obesity and estrogen as risk factors for gastroesophageal reflux symptoms. JAMA 2003;290:66-72.

12. Mathus-Vliegen EMH, Tytgat GNJ. Gastro-oesophageal Reflux in Obese Subjects: Influence of Overweight, Weight Loss and Chronic Gastric Balloon Distension. Scand J Gastroenterol 2002;37:1246-52.

13. Zacchi P, Mearin F, Humbert P, et al. Effect of obesity on gastroesophageal resistance to flow in man. Dig Dis Sci 1991;36:1473-80.

14. El-Serag HB, Graham DY, Satia JA, et al. Obesity Is an Independent Risk Factor for GERD Symptoms and Erosive Esophagitis. Am J Gastroenterol 2005;100:1243-50.

15. Kitchin LI. Rationale and Efficacy of Conservative Therapy for Gastroesophageal Reflux Disease. Arch Intern Med 1991;151:448.

16. Mercer CD, Dale Mercer C, Hanelin L, et al. Effect of obesity on esophageal transit. Am J Surg 1985;149:177-81.

17. Wilson LJ, Ma W, Hirschowitz BI. Association of Obesity With Hiatal Hernia and Esophagitis. Am J Gastroenterol 1999;94:2840-4.

18. Hampel H, Abraham NS, El-Serag HB. Meta-Analysis: Obesity and the Risk for Gastroesophageal Reflux Disease and Its Complications. Ann Intern Med 2005;143:199.

19. Spechler SJ, Fitzgerald RC, Prasad GA, et al. History, Molecular Mechanisms, and Endoscopic Treatment of Barrett's Esophagus. Gastroenterology 2010;138:854-69.

20. Rigaud D, Merrouche M, Le Moel G, et al. Factors of gastroesophageal acid reflux in severe obesity. Gastroenterol Clin Biol 1995;19:818-25.

21. Yeung KTD, Penney N, Ashrafian L, et al. Does Sleeve Gastrectomy Expose the Distal Esophagus to Severe Reflux? Ann Surg 2020;271:257-65.

22. Snyder B, Wilson E, Wilson T, et al. A randomized trial comparing reflux symptoms in sleeve gastrectomy patients with or without hiatal hernia repair. Surg Obes Relat Dis 2016;12:1681-8.

23. Gu L, Chen B, Du N, et al. Relationship Between Bariatric Surgery and Gastroesophageal Reflux Disease: a Systematic Review and Meta-analysis. Obes Surg 
2019;29:4105-13.

24. Koppman JS, Poggi L, Szomstein S, et al. Esophageal motility disorders in the morbidly obese population. Surg Endosc 2007;21:761-4.

25. Oor JE, Roks DJ, Unlu C, et al. Laparoscopic sleeve gastrectomy and gastroesophageal reflux disease: a systematic review and meta-analysis. Am J Surg 2016;211:250-67.

26. Braghetto I, Csendes A, Korn O, et al. Gastroesophageal reflux disease after sleeve gastrectomy. Surg Laparosc Endosc Percutan Tech 2010;20:148-53.

27. Gorodner V, Buxhoeveden R, Clemente G, et al. Does laparoscopic sleeve gastrectomy have any influence on gastroesophageal reflux disease? Preliminary results. Surg Endosc 2015;29:1760-8.

28. Himpens J, Dapri G, Cadière GB. A prospective randomized study between laparoscopic gastric banding and laparoscopic isolated sleeve gastrectomy: results after 1 and 3 years. Obes Surg 2006;16:1450-6.

29. Goitein D, Sakran N, Rayman S, et al. Barium swallow for hiatal hernia detection is unnecessary prior to primary sleeve gastrectomy. Surg Obes Relat Dis 2017;13:138-42.

30. Ghassemian AJ, MacDonald KG, Cunningham PG, et al. The Workup for Bariatric Surgery Does Not Require a Routine Upper Gastrointestinal Series. Obes Surg 1997;7:16-8.

31. Schirmer B, Erenoglu C, Miller A. Flexible endoscopy in the management of patients undergoing Roux-en- $\mathrm{Y}$ gastric bypass. Obes Surg 2002;12:634-8.

32. Saarinen T, Kettunen U, Pietilainen K, et al. Is preoperative gastroscopy necessary before sleeve gastrectomy and Rouxen-Y gastric bypass? Surg Obes Relat Dis 2018;14:757-62.

33. Melendez-Rosado J, Gutierrez-Blanco D, Schneider A, et al. Impact of preoperative wireless $\mathrm{pH}$ monitoring in the evaluation of esophageal conditions prior to bariatric surgery in a severely obese patient population. Surg Obes Relat Dis 2019;15:288-94.

34. Frazzoni M, Piccoli M, Conigliaro R, et al. Refractory gastroesophageal reflux disease as diagnosed by impedance-pH monitoring can be cured by laparoscopic fundoplication. Surg Endosc 2013;27:2940-6.

35. Moore M, Afaneh C, Benhuri D, et al. Gastroesophageal reflux disease: A review of surgical decision making. World J Gastrointest Surg 2016;8:77-83.

36. Kawahara NT, Alster C, Maluf-Filho F, et al. Modified Nissen fundoplication: laparoscopic anti-reflux surgery after Roux-en-Y gastric bypass for obesity. Clinics 2012;67:531-3.
37. Chen RH, Lautz D, Gilbert RJ, et al. Antireflux operation for gastroesophageal reflux after Roux-en-y gastric bypass for obesity. Ann Thorac Surg 2005;80:1938-40.

38. Blanco DG, Quirante FP, Montorfano L, et al. Outcomes of barbed suture hiatal hernia repair during bariatric surgery - A single institution experience. Surg Obesity Related Dis 2016;12:S232.

39. Noel P, Nedelcu M, Schneck AS, et al. Revised sleeve gastrectomy: another option for weight loss failure after sleeve gastrectomy. Surg Endosc 2014;28:1096-102.

40. Gálvez-Valdovinos R, Cruz-Vigo JL, Marin-Santillan E, et al. Cardiopexy with Ligamentum Teres in Patients with Hiatal Hernia and Previous Sleeve Gastrectomy: An Alternative Treatment for Gastroesophageal Reflux Disease. Obes Surg 2015;25:1539-43.

41. Moon RC, Teixeira AF, Treto J, et al. Cardiopexy at the Time of Sleeve Gastrectomy as a Preventive Measure for Reflux. Surg Laparosc Endosc Percutan Tech 2020;30:464-6.

42. Fishman MB, Perry ZH, Lantsberg L. Gastroesophageal Reflux Disease after Bariatric Surgery. A New Way for the Treatment and Prevention. J Obesity Bariatrics 2017;4:1-5.

43. Skubleny D, Switzer NJ, Dang J, et al. LINX magnetic esophageal sphincter augmentation versus Nissen fundoplication for gastroesophageal reflux disease: a systematic review and meta-analysis. Surg Endosc 2017;31:3078-84.

44. Yeung KTD, Penney N, Ashrafian L, et al. Does Sleeve Gastrectomy Expose the Distal Esophagus to Severe Reflux?: A Systematic Review and Meta-analysis. Ann Surg 2020;271:257-65.

45. Yilmaz H, Ece I, Sahin M. Revisional Surgery After Failed Laparoscopic Sleeve Gastrectomy: Retrospective Analysis of Causes, Results, and Technical Considerations. Obes Surg 2017;27:2855-60.

46. Boru CE, Greco F, Giustacchini P, et al. Short-term outcomes of sleeve gastrectomy conversion to R-Y gastric bypass: multi-center retrospective study. Langenbecks Arch Surg 2018;403:473-9.

47. Kristo I, Paireder M, Jomrich G, et al. Modern Esophageal Function Testing and Gastroesophageal Reflux Disease in Morbidly Obese Patients. Obes Surg 2019;29:3536-41.

48. Kaltenbach T, Crockett S, Gerson LB. Are lifestyle measures effective in patients with gastroesophageal reflux disease? An evidence-based approach. Arch Intern Med 2006;166:965-71.

49. Jacobson BC, Somers SC, Fuchs CS, et al. Body-mass 
index and symptoms of gastroesophageal reflux in women. N Engl J Med 2006;354:2340-8.

50. Fujiwara Y, Arakawa T, Fass R. Gastroesophageal reflux disease and sleep disturbances. J Gastroenterol 2012;47:760-9.

51. Chey WD, Mody RR, Izat E. Patient and physician satisfaction with proton pump inhibitors (PPIs): are there opportunities for improvement? Dig Dis Sci 2010;55:3415-22.

52. Khan M, Santana J, Khan M, et al. Medical treatments in the short term management of reflux oesophagitis. Cochrane Database Syst Rev 2007:CD003244.

53. Håkansson B, Montgomery M, Cadiere GB, et al. Randomised clinical trial: transoral incisionless fundoplication vs. sham intervention to control chronic GERD. Aliment Pharmacol Ther 2015;42:1261-70.

54. Lipka S, Kumar A, Richter JE. No evidence for efficacy of radiofrequency ablation for treatment of gastroesophageal reflux disease: a systematic review and meta-analysis. Clin Gastroenterol Hepatol 2015;13:1058-67.e1.

55. Noar M, Squires P, Noar E, et al. Long-term maintenance effect of radiofrequency energy delivery for refractory GERD: a decade later. Surg Endosc 2014;28:2323-33.

56. Cheung D, Switzer NJ, Gill RS, et al. Revisional bariatric surgery following failed primary laparoscopic sleeve gastrectomy: a systematic review. Obes Surg 2014;24:1757-63.

Cite this article as: Aleman R, Lo Menzo E, Szomstein $\mathrm{S}$, Rosenthal RJ. De novo gastroesophageal reflux disease esophageal surgery in bariatrics: a literature review and analysis of the current treatment options. Ann Transl Med 2021;9(10):899. doi: 10.21037/atm-20-5890
57. Santoro S, Lacombe A, Gaspar de Aquino CG, et al. Sleeve gastrectomy with anti-reflux procedures. Einstein 2014;12:287-94.

58. Alhaj Saleh A, Janik MR, Mustafa RR, et al. Does Sleeve Shape Make a Difference in Outcomes? Obes Surg 2018;28:1731-7.

59. Nau P, Jackson HT, Aryaie A, et al. Surgical management of gastroesophageal reflux disease in the obese patient. Surg Endosc 2020;34:450-7.

60. Frezza EE, Ikramuddin S, Gourash W, et al. Symptomatic improvement in gastroesophageal reflux disease (GERD) following laparoscopic Roux-en-Y gastric bypass. Surg Endosc 2002;16:1027-31.

61. Mejía-Rivas MA, Herrera-López A, Hernandez-Calleros J, et al. Gastroesophageal reflux disease in morbid obesity: the effect of Roux-en-Y gastric bypass. Obes Surg 2008;18:1217-24.

62. Madalosso CAS, Gurski RR, Callegari-Jacques SM, et al. The Impact of Gastric Bypass on Gastroesophageal Reflux Disease in Morbidly Obese Patients. Ann Surg 2016;263:110-6.

63. Petersen WV, Meile T, Kuper MA, et al. Functional importance of laparoscopic sleeve gastrectomy for the lower esophageal sphincter in patients with morbid obesity. Obes Surg 2012;22:360-6. 